\title{
Influence of postharvest application of Nigella sativa oil and starch on the physiological, biochemical and quality parameters of pomegranate arils cv. 'BHAGWA'
}

\author{
P. Sridevi ${ }^{1}$ and V. Vijaya Bhaskar* \\ Department of Horticulture, College of Horticulture, Dr. Y.S.R. Horticultural University, \\ Anantharajupeta, KADAPA(A.P.) INDIA (Email : vijayabaachi@gmail.com)
}

\begin{abstract}
Pomegranate (Punica granatum L.) is a tropical fruit and grown in many parts of the world predominantly in the Mediterranean region. Fresh seeds (arils) are consumed. Arils contain around 80 per cent of juice and 20 per cent of seed. However, quick browning and desiccation are the important concerns of quality during postharvest storage. To prevent quick moisture loss and browning of arils, applied different concentrations of black cumin seed oil and starch as a coating to improve the shelf life and quality of arils. Results showed that pomegranate arils coated with Nigella sativa oil at $200 \mathrm{ppm}$ concentration recorded significantly lowest total sugars content and titrable acidity during the initial stages, whereas at later stages recorded significantly highest total sugars (14.408 and 13.687 , respectively on days 12 and 16$)$ and titrable acidity $(0.382$ and 0.358 on day 12 and 16). Further, arils treated with Nigella sativa oil at $200 \mathrm{ppm}$ concentration recorded significantly lowest per cent of spoilage, physiological loss in weight and recorded significantly highest antioxidant activity, ascorbic acid and anthocyanins content. At the end, it was noticed that edible coating did not affect the natural flavour of pomegranate arils.
\end{abstract}

Key Words : Antioxidant activity, Anthocyanins, Ascorbic acid, Nigella sativa oil, Pomegranate arils, Starch

View Point Article : Sridevi, P. and Bhaskar, V. Vijaya (2018). Influence of postharvest application of Nigella sativa oil and starch on the physiological, biochemical and quality parameters of pomegranate arils cv. 'BHAGWA'. Internat. J. agric. Sci., 14 (1) : 247-253, DOI:10.15740/ HAS/IJAS/14.1/247-253.

Article History : Received : 24.10.2017; Revised : 12.12.2017; Accepted : 24.12.2017

\footnotetext{
* Author for correspondence:

${ }^{1}$ Department of Fruit Science, College of Horticulture, Dr. Y.S.R. Horticultural University, Venkataramannagudem, WEST GODAVARI (A.P.) INDIA
} 